\title{
MORTALITY IN THE LONDON BOROUGHS, 1950-52, WITH SPECIAL REFERENCE TO RESPIRATORY DISEASE
}

\author{
BY \\ DAVID HEWITT \\ From the Social Medicine Unit, University of Oxford
}

This paper is based on a study of mortality in the Administrative County of London in the three years immediately surrounding the most recent Census, during which period just over 120,000 London residents died. For some of the rarer causes of death it would have been desirable to study a longer period, but there were several reasons for not attempting this. In the first place there was the risk of error in local population figures at intervals of more than 18 months from the Census date. Secondly, a new revision of the International Classification of Diseases (World Health Organization, 1949) came into operation in 1950, giving rise to certain discontinuities in the statistics. Thirdly, and much more important for local mortality studies, a change was made in 1953 in the official definition of the "usual residence" of deceased persons. As a result all deaths in hospitals for the chronic sick and in mental and mental deficiency hospitals have been assigned, from 1953 onwards, to the area of the hospital, whether or not the patient had originally been admitted from that area (Registrar General, 1954, Corrigenda). This change has had a serious effect on the statistics for London, most of which is served by chronic and mental hospitals outside the county boundary. Important features of local mortality have been obliterated by the change and new anomalies have appeared. Unless there is a reversion to the practice which made British mortality statistics for many decades an example to the world, general studies of local mortality must come to an end with 1952.

\section{MATERIAL AND Methods}

All the raw material for this study has been drawn from official publications (see References, under Registrar General for England and Wales). Numbers of deaths have been taken from the Statistical Reviews of the Registrar General for the years 1930-32 and 1942-54, and also from the Annual Report of the County Medical Officer of Health for the County of London, 1952 (Scott, 1953). Population figures have been taken from the 1931 Statistical Review, the London County Report of the 1931 Census, from the London and Essex County Reports of the 1951 Census and from the 1951 One Per Cent Sample Tables. Figures for atmospheric pollution have been taken from the returns collated at the Fuel Research Station, Greenwich (Department of Scientific and Industrial Research, 1955, 1956).

All standardizations have been performed by the "indirect" method using ten age-groups in each sex (0-4, and 10-year groups from 5-14 to 85+). The term Standardized Mortality Ratio (S.M.R. passim) has been used for the ratio (multiplied by 100) of any actual number of deaths to the corresponding "expected" number. Except where otherwise specified, all expectations are based on the contemporary mortality of England and Wales as a whole. In the text the term significant has been reserved for departures from expectation and correlation coefficients which yield a value of $\chi^{2}$ or of $t$ beyond the 1 per cent. point. The correlation coefficients have all been calculated by the product-moment method without introduction of any special weighting. The two smallest local government areas of London, whose S.M.R.s have the largest sampling error (Holborn and City), happen to be adjacent and have therefore been treated as a single unit in all calculations except those based on the nine Public Health Divisions.

The paper falls into three parts. Part I presents a general outline of mortality from all causes, leading to a special consideration of respiratory diseases. Part II considers how far the local variations in mortality can be accounted for in terms of socio-economic differences. In Part III an attempt is made to trace a relationship between atmospheric pollution and the death rates from respiratory and other diseases. 
Part I. General Features of Mortality IN LONDON

MORTAlity From All CAUSES.-It is convenient to start with "mortality from all causes" since sampling error is here at a minimum and the findings cannot be affected by errors in diagnosis.

The total number of deaths occurring during 195052 was just $1 \cdot 1$ per cent. greater than the expected number computed from national mortality rates, very similar to the excess of 1.3 per cent. in the three years surrounding the previous census of 1931 (Table I). This close correspondence between the actual and expected aggregate of deaths, however, masks important differences. In addition to inter-borough variations, certain sex and age groups of the whole London population showed significant departures from standard. In both periods male mortality was some 7 per cent. above and female mortality 4-5 per cent. below the national standard. In 1950-52 the male S.M.R. from all causes in London was nearly

TABLE I

STANDARDIZED MORTALITY RATIOS FOR DEATHS FROM ALL CAUSES, BY BOROUGH AND SEX. PERIODS 1930-32 AND 1950-52

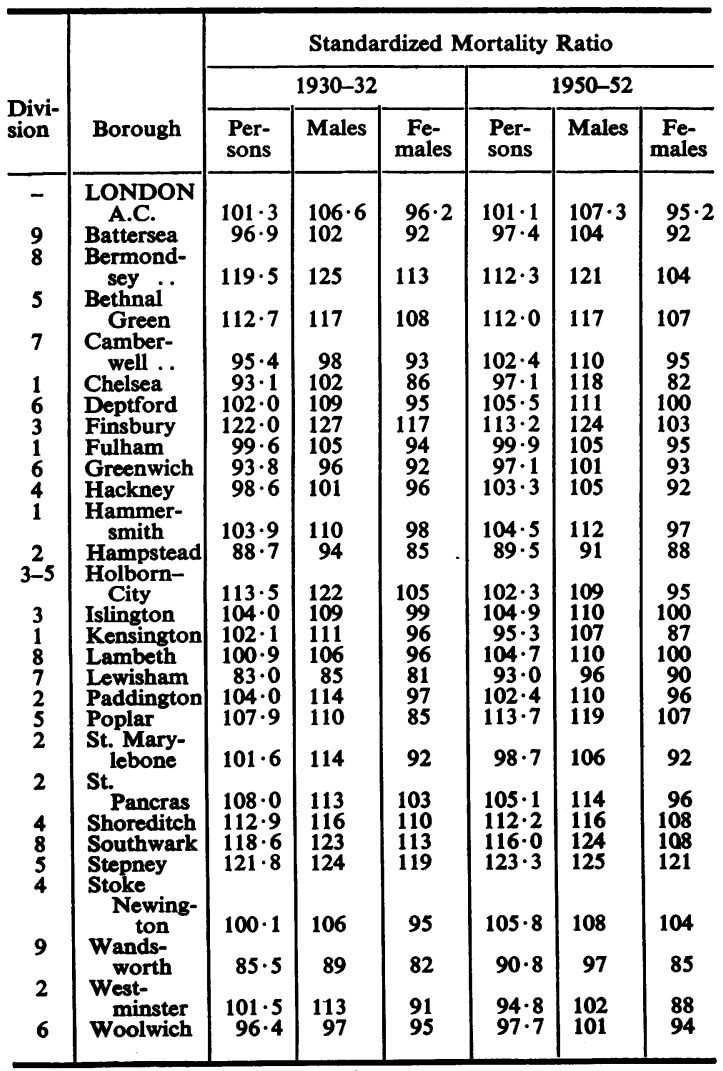

13 per cent. greater than the female S.M.R., and this difference alone (associated with a value of $\chi^{2}$ for one degree of freedom of well over 400 ) shows that there must have been something in the London environment particularly adverse to the survival of men. At the level of relative mortality achieved by the women of London, the number of male deaths would have been fewer by about 7,000 , or between six and seven per day.

London death rates were low at ages under 5 years and again in early adult life, but in middle life they were comparatively high, particularly among males aged 45-64 (S.M.R. of 114, see Table II). The low death rates of the young adults may be due to selective migration of healthy persons to London at the beginning of their careers. The deviations from standard in childhood and in middle life are more likely to be true environmental effects. The advantageous position of young children in London seems to be a recent development, but an excessive mortality among middle-aged men was also found in the figures for 1930-32 (see Table II). Even as long ago as the 1860 s London mortality showed a distinct peak, relative to the mortality of 345 "healthy districts", between the ages of 45 and 64 (Farr, 1885).

\section{TABLE II}

STANDARDIZED MORTALITY RATIOS (ALL CAUSES), BY AGE AND SEX FOR THE YEARS 1930-32 AND 1950-52. WHOLE OF LONDON A.C.

\begin{tabular}{|c|c|c|c|c|c|c|c|c|c|}
\hline \multicolumn{2}{|c|}{ Age (yrs) $\ldots$} & $0-4$ & $5-14$ & $15-24$ & $25-44$ & $45-64$ & $65-74$ & $75+$ & $\begin{array}{l}\text { All } \\
\text { Ages }\end{array}$ \\
\hline $\begin{array}{l}1930- \\
32\end{array}$ & $\begin{array}{c}\text { Males } \\
\text { Fe- } \\
\text { males }\end{array}$ & $\begin{array}{l}107 \\
109\end{array}$ & $\begin{array}{l}97 \\
94\end{array}$ & $\begin{array}{l}98 \\
92\end{array}$ & $\begin{array}{r}103 \\
93\end{array}$ & $\begin{array}{l}116 \\
100\end{array}$ & $\begin{array}{r}103 \\
93\end{array}$ & $\begin{array}{r}102 \\
94\end{array}$ & $\begin{array}{r}107 \\
96\end{array}$ \\
\hline $\begin{array}{r}1950- \\
52\end{array}$ & $\begin{array}{l}\text { Males } \\
\text { Fe- } \\
\text { males }\end{array}$ & $\begin{array}{l}89 \\
88\end{array}$ & $\begin{array}{l}98 \\
91\end{array}$ & $\begin{array}{l}78 \\
81\end{array}$ & $\begin{array}{l}99 \\
97\end{array}$ & $\begin{array}{r}114 \\
99\end{array}$ & $\begin{array}{r}110 \\
94\end{array}$ & $\begin{array}{r}105 \\
95\end{array}$ & $\begin{array}{r}107 \\
95\end{array}$ \\
\hline
\end{tabular}

A possible reason for the concentration of London's net excess of deaths in a particular sex and age group will appear later, but two facts are worth notice at this point:

(i) The S.M.R. for females, though not greater than 100 at any age, was also highest between 45 and 64 .

(ii) The proportion of all deaths which are ascribed to diseases of the respiratory system is always higher for men than for women, and higher between 45 and 64 than at other periods of life.

The S.M.R.s for individual boroughs show, as would be expected, a considerable scatter, ranging from 89.5 in Hampstead to 123.3 in Stepney (Table I). The pattern of local mortality was very like that of 20 years earlier, as is shown by a correlation coefficient of +0.890 between the borough S.M.R.s for the two periods. Such changes as did occur in 
the standing of individual boroughs bore no obvious relation to the shifts of population brought about by slum clearance and bombing. The seven boroughs with the highest S.M.R.s in 1950-52 formed an almost solid block in east-central London, leaving the City as an enclave of relatively low mortality.* In each of the 28 boroughs, the male S.M.R. exceeded the female S.M.R., in three cases by more than 20 points (Chelsea, Kensington, and Finsbury). In general male and female S.M.R.s showed similar local variations $(r=+0.697)$.

It is of interest to know whether there was any link between the age pattern and the geographical pattern of London mortality. For this purpose a comparison was made (Fig. 1) between the S.M.R.s for various age groups in the five boroughs where mortality was highest (Stepney, Southwark, Poplar, Finsbury, and Bermondsey) and the five where it was lowest (Hampstead, Wandsworth, Kensington, Lewisham, and Westminster). S.M.R.s for females in the "best" boroughs follow an erratic course which is hard to interpret. But in the case of males the

- By enumerating all the pairs of boroughs with common boundaries, it is found that the probability that two boroughs chosen at random will be contiguous is $0 \cdot 16$. The probability that three boroughs will form an undivided set is 0.06 , for seven boroughs the probability must be very small. This serves to confirm that the clustering together of boroughs with high S.M.R.s is not a chance effect.

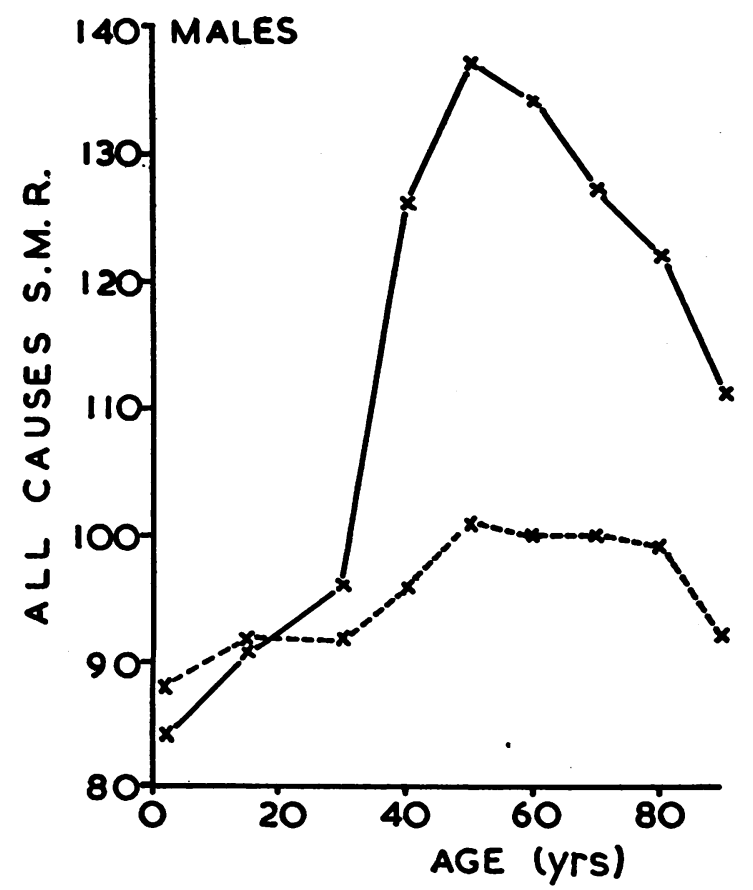

result is quite clear: the five "worst" boroughs show a very high peak of relative mortality at the age of about 50, while the S.M.R.s for the five "best" boroughs run comparatively close to the national standard throughout life. This suggests that a common factor may be involved in the production of mortality variations within London and of the overall excess of deaths among middle-aged men.

MORTALITY FROM RESPIRATORY AND OTHER CAUSES.-As soon as individual causes of death are considered, the question of local variations in diagnostic practice arises. It is generally felt that "modern" or sophisticated diagnoses are more likely to be achieved in London than in the provinces. There is an obvious risk that such diagnostic variation may give rise to spurious differences between the London and the national S.M.R. for particular causes (this problem is discussed in some detail below). There is, however, a prima facie case for supposing that the spurious element in borough S.M.R.s is of secondary importance. Suppose, for example, that a proportion of the deaths caused by disease $X$ tended in some boroughs to be attributed to disease $Y$. Other things being equal, this will give rise to a negative correlation between the borough death rates from $X$ and $Y$.

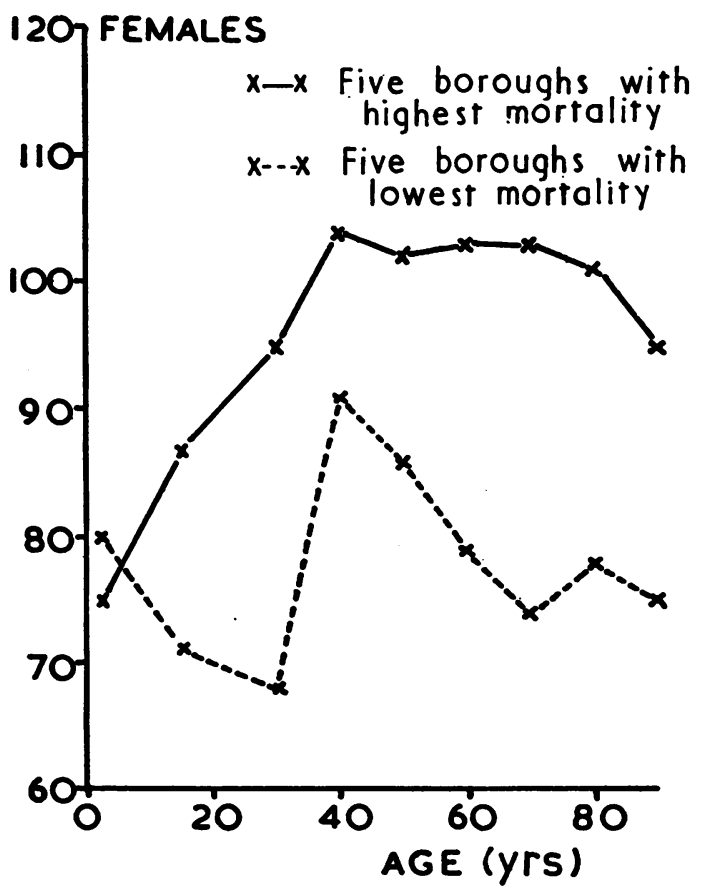

FIo. 1.-S.M.R.s from all causes by age and sex, in the five metropolitan boroughs with the highest mortality and in the five with the lowest mortality 
When these rates are positively correlated then it is clear that the local pattern of mortality from both $X$ and $Y$ must have been determined by factors which outweigh any effect of variations in the ability to recognize $X$.

S.M.R.s were calculated for 39 separate causes of death, and were found to range from 167 (syphilitic disease) to 39 (senility). These results are summarized in the appendix. The main features of the analysis may be brought out by quoting the figures for certain broad sections of the "International Classification of Diseases" (W.H.O., 1949):

\begin{tabular}{|c|c|c|c|}
\hline $\begin{array}{l}\text { I.C.D. } \\
\text { Numbers }\end{array}$ & Disease Group & S.M.R. & $\begin{array}{l}\text { Estimated Excess } \\
\text { or Deficiency } \\
\text { of Deaths }\end{array}$ \\
\hline $140-205$ & Malignant .. & $114 \cdot 7$ & $+2,929$ \\
\hline $\begin{array}{r}330-334 \\
400-468 \\
590-594\end{array}$ & Cardiovascular-renal & $91 \cdot 0$ & $-5,484$ \\
\hline $\begin{array}{c}470-527 \\
763\end{array}$ & Respiratory & $127 \cdot 3$ & $+3,958$ \\
\hline 一 & Others & $99 \cdot 5$ & -662 \\
\hline
\end{tabular}

The greatest proportionate departure from expectation occurred in the respiratory section of the I.C. D., which may be subdivided as follows:

\begin{tabular}{c|ccc|c|c}
\hline $\begin{array}{c}\text { I.C.D. } \\
\text { Numbers }\end{array}$ & \multicolumn{2}{|c|}{ Disease Group } & S.M.R. & $\begin{array}{c}\text { Estimated Excess } \\
\text { or Deficiency } \\
\text { of Deaths }\end{array}$ \\
\hline $480-483$ & Influenza &.. & $\ldots$ & 74 & -434 \\
\hline $490-493$ & Bronchitis &.. & $\ldots$ & 144 & $+3,099$ \\
\hline $\begin{array}{c}500-502 \\
763\end{array}$ & Pneumonia &.. & $\ldots$ & 127 & $+1,242$ \\
\hline- & Other Respiratory &.. & 105 & +51 \\
\hline
\end{tabular}

Thus bronchitis and pneumonia produced well over 4.000 excess deaths in London during 1950-52. But this was by no means the whole of the excess attributed to diseases of the respiratory system, for more than half of the excess deaths in the malignant section of the I.C.D. were caused by cancer of the trachea, bronchus, and lung (S.M.R. 155). In addition there was an excess of more than 500 deaths from respiratory tuberculosis (S.M.R. 120). Taken together these four diseases of the respiratory system yielded 6,513 more deaths than would have occurred at the rates ruling in England and Wales generally, an excess of $37 \cdot 3$ per cent.

It is at once obvious that no tendency on the part of London doctors to confuse diagnoses within this group can explain away the high S.M.R.s for these four diseases. The group could, however, contain a number of deaths which in the provinces would have been attributed to cardiovascular causes. This possibility cannot be properly assessed until the age and borough distribution of respiratory diseases has been considered.

As Fig. 2 shows, the London S.M.R.s for respiratory disease varied condiserably with age. In each sex, respiratory mortality was significantly below the national standard during early childhood, and increased more or less regularly throughout life. For men the rate of increase was approximately 1 per cent. of the standard risk per year of life, for women rather less. When S.M.R.s for the four respiratory diseases were considered separately, each showed a rising trend with age in each sex, though bronchitis deaths were significantly in excess in early childhood and showed no further relative rise until the age of 50. It is interesting to note the parallel between these figures and those of a recent study of cancer among British immigrants in New Zealand (Eastcott, 1956). Compared with the native-born population, British immigrants had an excessive risk of death from cancer of the lung (but of no other site), and this excess was significantly greater for persons who had lived in Britain until they were 30 years old than for those who migrated at an earlier age. Thus there emerges from both studies a consistent relationship between duration of exposure to the putatively noxious environment and risk of later death from respiratory disease.

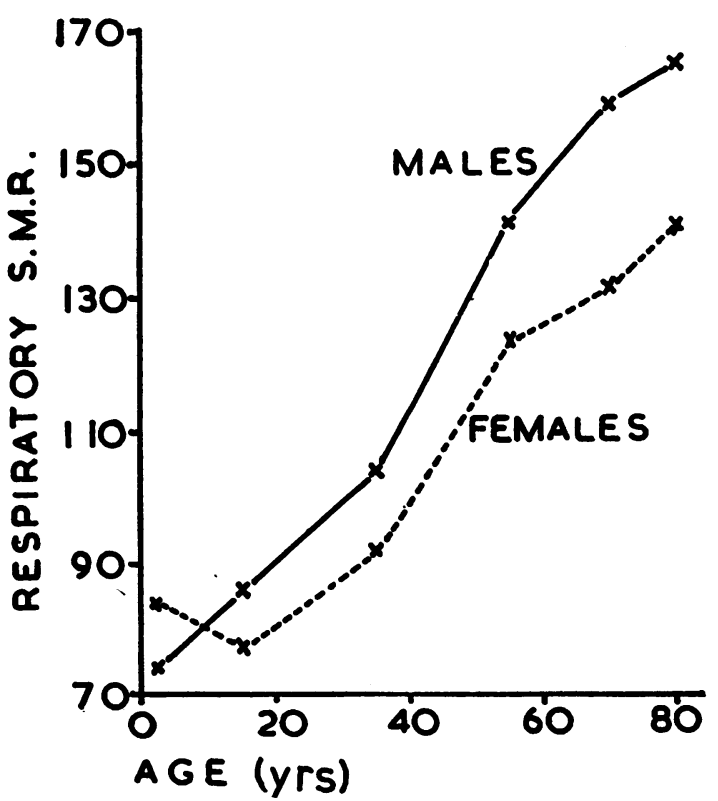

Fio. 2.-S.M.R. for aggregate of four respiratory diseases, by age and sex, whole of London County 
Table III shows borough S.M.R.s for the four respiratory diseases, separately and together, and for the aggregate of other deaths. A striking feature of this Table is the wide range of S.M.R.s for the respiratory group (95 to 190 ) compared with other causes (87 to 113). Since the number of deaths from the four respiratory diseases was almost exactly onequarter of the number from all other causes, the variation due to sampling error should be about twice as great for the respiratory S.M.R.s as for the others. But sampling error cannot de a very important element in the variation of the respiratory group S.M.R.s, since ratios calculated separately for the males and females of each borough were found to be quite highly correlated $(r=+0 \cdot 845)$. This "splithalf" test shows that the respiratory S.M.R.s must be a fairly reliable measure of some locally varying factor or factors. By this criterion the respiratory group S.M.R. was a more systematic variable than the S.M.R. based on the larger but more heterogeneous aggregate of deaths from all other causes (male-female correlation of only $+0 \cdot 293$ ).

TABLE III

BOROUGH S.M.R.S FOR FOUR RESPIRATORY DISEASES AND FOR ALL OTHER CAUSES. SEXES COMBINED. (Brackets indicate an S.M.R. based on less than 50 deaths)

\begin{tabular}{|c|c|c|c|c|c|c|}
\hline \multirow[b]{2}{*}{ Borough } & \multicolumn{6}{|c|}{ Standardized Mortality Ratio } \\
\hline & $\begin{array}{l}\text { Bron- } \\
\text { chitis }\end{array}$ & $\begin{array}{l}\text { Pneu- } \\
\text { monia }\end{array}$ & $\begin{array}{l}\text { Cancer } \\
\text { of the } \\
\text { Lung, } \\
\text { etc. }\end{array}$ & $\begin{array}{l}\text { Res- } \\
\text { pira- } \\
\text { tory } \\
\text { Tuber- } \\
\text { culosis }\end{array}$ & $\begin{array}{c}\text { Aggre- } \\
\text { gate } \\
\text { of four } \\
\text { Res- } \\
\text { pira- } \\
\text { tory } \\
\text { Dis- } \\
\text { eases }\end{array}$ & $\begin{array}{c}\text { ALL } \\
\text { OTHER } \\
\text { CAUSES }\end{array}$ \\
\hline $\begin{array}{l}\text { LONDON } \\
\text { A.C. .. } \\
\text { Battersea... } \\
\text { Bermondsey } \\
\text { Bethnal }\end{array}$ & $\begin{array}{l}144 \\
145 \\
197\end{array}$ & $\begin{array}{l}127 \\
106 \\
165\end{array}$ & $\begin{array}{l}155 \\
139 \\
180\end{array}$ & $\begin{array}{l}120 \\
131 \\
137\end{array}$ & $\begin{array}{l}137 \\
131 \\
176\end{array}$ & $\begin{array}{r}95 \\
92 \\
101\end{array}$ \\
\hline $\begin{array}{l}\text { Green ... } \\
\text { Camberwell } \\
\text { Chelsea .. } \\
\text { Deptford.. } \\
\text { Finsbury } \\
\text { Fulham .. } \\
\text { Greenwich } \\
\text { Hackney } \\
\text { Hammer- }\end{array}$ & $\begin{array}{l}220 \\
178 \\
81 \\
160 \\
188 \\
157 \\
124 \\
168\end{array}$ & $\begin{array}{r}163 \\
95 \\
154 \\
136 \\
175 \\
149 \\
100 \\
154\end{array}$ & $\begin{array}{l}220 \\
151 \\
162 \\
148 \\
214 \\
151 \\
144 \\
150\end{array}$ & $\begin{array}{l}(95) \\
111 \\
(97) \\
161 \\
171 \\
109 \\
142 \\
109\end{array}$ & $\begin{array}{l}184 \\
141 \\
116 \\
152 \\
186 \\
146 \\
124 \\
151\end{array}$ & $\begin{array}{r}99 \\
96 \\
94 \\
97 \\
101 \\
92 \\
92 \\
95\end{array}$ \\
\hline $\begin{array}{l}\text { smith - .. } \\
\text { Hampstead } \\
\text { Holborn-City } \\
\text { Islington } \\
\text { Kensington } \\
\text { Lambeth } \\
\text { Lewisham } \\
\text { Paddington } \\
\text { Poplar }\end{array}$ & $\begin{array}{r}164 \\
85 \\
120 \\
167 \\
99 \\
150 \\
118 \\
126 \\
208\end{array}$ & $\begin{array}{r}134 \\
96 \\
147 \\
142 \\
122 \\
134 \\
93 \\
124 \\
133\end{array}$ & $\begin{array}{l}166 \\
129 \\
146 \\
188 \\
155 \\
155 \\
119 \\
145 \\
173\end{array}$ & $\begin{array}{r}120 \\
79 \\
(155) \\
119 \\
79 \\
130 \\
87 \\
132 \\
128\end{array}$ & $\begin{array}{r}149 \\
95 \\
138 \\
156 \\
111 \\
143 \\
107 \\
130 \\
168\end{array}$ & $\begin{array}{r}97 \\
89 \\
96 \\
96 \\
93 \\
98 \\
91 \\
98 \\
104\end{array}$ \\
\hline $\begin{array}{l}\text { bone... } \\
\text { St. Pancras } \\
\text { Shoreditch } \\
\text { Southwark } \\
\text { Stepney ... } \\
\text { Stoke }\end{array}$ & $\begin{array}{l}100 \\
143 \\
235 \\
218 \\
187\end{array}$ & $\begin{array}{l}110 \\
153 \\
148 \\
173 \\
175\end{array}$ & $\begin{array}{l}145 \\
209 \\
189 \\
177 \\
163\end{array}$ & $\begin{array}{r}93 \\
151 \\
(131) \\
163 \\
178\end{array}$ & $\begin{array}{l}110 \\
159 \\
187 \\
190 \\
178\end{array}$ & $\begin{array}{r}97 \\
96 \\
99 \\
103 \\
113\end{array}$ \\
\hline $\begin{array}{l}\text { Newington } \\
\text { Wandsworth } \\
\text { Westminster } \\
\text { Woolwich }\end{array}$ & $\begin{array}{r}173 \\
123 \\
88 \\
104\end{array}$ & $\begin{array}{r}173 \\
90 \\
128 \\
121\end{array}$ & $\begin{array}{l}144 \\
134 \\
122 \\
151\end{array}$ & $\begin{array}{r}(106) \\
112 \\
132 \\
116\end{array}$ & $\begin{array}{l}157 \\
114 \\
112 \\
119\end{array}$ & $\begin{array}{l}97 \\
87 \\
92 \\
94\end{array}$ \\
\hline
\end{tabular}

Some of the borough S.M.R.s for individual respiratory causes were extremely high. A mortality of more than double the national standard was recorded for bronchitis in four boroughs (Bethnal Green, Poplar, Shoreditch, and Southwark) and for lung cancer in three (Bethnal Green, Finsbury, and St. Pancras). Nineteen of the 28 boroughs had excess deaths from all four diseases. The principal concentration of respiratory mortality, as of mortality from all causes, was in the east-central area. The seven boroughs already mentioned as forming a compact area of high all-causes mortality took the highest seven places both for respiratory deaths and for the balance of other causes. The clustering together of boroughs with high respiratory death-rates was even more pronounced than in the case of the all-causes death rates. There were twelve boroughs with respiratory S.M.R.s of over 150, and these formed a single continuous area, to which may be added West Ham (adjacent to Poplar but outside London) with a respiratory S.M.R. of 153 .

Table IV shows the intercorrelations of the S.M.R.S given in Table III. All six correlations within the respiratory group were positive and the three which did not involve tuberculosis were significantly large. It follows that borough differences in the recorded mortality from respiratory diseases (like the difference between London and the rest of the country) cannot be explained in terms of differeng allocation of diagnoses within the respiratory group. Moreover, the four respiratory diseases, severally and collectively, also showed significant positive correlation with the mortality from other causes (right hand column of Table IV). This finding reduces the likelihood that variations in the propensity to diagnose respiratory disease can have had any important effect on the borough S.M.R.s.

TABLE IV

CORRELATIONS BETWEEN BOROUGH S.M.R.S SHOWN IN TABLE III

\begin{tabular}{l|c|c|c|c}
\hline & Pneumonia & $\begin{array}{c}\text { Cancer of } \\
\text { Lung, etc. }\end{array}$ & $\begin{array}{c}\text { Respiratory } \\
\text { Tuberculosis }\end{array}$ & $\begin{array}{c}\text { All Other } \\
\text { Causes }\end{array}$ \\
\hline Bronchitis .. & +0.563 & +0.698 & +0.413 & +0.468 \\
\hline Pneumonia .. & - & +0.654 & +0.471 & +0.671 \\
\hline $\begin{array}{c}\text { Cancer of } \\
\text { Lung, etc. }\end{array}$ & - & - & +0.324 & +0.535 \\
\hline $\begin{array}{c}\text { Aggregate of } \\
\text { four Respira- } \\
\text { tory Diseases }\end{array}$ & - & - & - & +0.750 \\
\hline
\end{tabular}

Critical values of the correlation coefficient for 28 pairs of observations: 5 per cent., $0.374 ; 2$ per cent., $0.438 ; 1$ per cent., $0.479 ; 0.1$ per cent., $0 \cdot 588$. 
Respiratory Mortality in Individual Years.Though the period chosen for study was short it contained two exceptional events: the influenza epidemic of January, 1951, and the smog episode of December, 1952. There was therefore a possibility that the picture presented by statistics for 1950-52 was not typical of the usual state of affairs in London. To check this, further S.M.R.s were calculated relating to individual years for two sections of London County: Section ' $A$ ' comprising the block of twelve boroughs whose respiratory group S.M.R.s exceeded 150 during 1950-52, and Section ' $B$ ' the remaining sixteen boroughs together with the City. These are shown in Table V. As was expected the influenza epidemic of 1951 had no great effect on the London S.M.R.s, since respiratory mortality in the country as a whole, from which the expected numbers of deaths were calculated, was also high in that year. Futrher evidence that the local pattern of respiratory mortality in London was not influenced by the epidemic is provided by the S.M.R.s for influenza itself in Sections A and B, which were 72 and 75 respectively (period 1950-52). In 1952 there was an unusually heavy mortality from respiratory disease in London as a whole, but this too was without effect on the contrast between Sections A and B (see last column of Table V). That is, the excessive mortality in east-central London relative to the rest of the county was very much the same in the influenza year and the smog year as it had been during the preceding three "normal" years. Figures for 1953 and 1954 show a smaller contrast between the two sections, but this is almost certainly an artificial change produced by the alteration in registration procedure already mentioned.

TABLE V

S.M.R.S FROM RESPIRATORY DISEASE IN TWO SECTIONS OF LONDON. INDIVIDUAL YEARS 1948-54

\begin{tabular}{|c|c|c|c|c|}
\hline \multirow[b]{2}{*}{ Year } & \multicolumn{3}{|c|}{ Standardized Mortality Ratio in } & \multirow{2}{*}{$\begin{array}{l}\text { Ratio of } \\
\text { A to B }\end{array}$} \\
\hline & $\begin{array}{l}\text { Whole } \\
\text { County }\end{array}$ & $\underset{A}{\text { Section }}$ & $\underset{\text { B }}{\text { Section }}$ & \\
\hline $\begin{array}{l}1948 \\
1949 \\
1950 \\
1951 \\
1952\end{array}$ & $\begin{array}{l}134 \cdot 8 \\
130 \cdot 9 \\
125 \cdot 8 \\
133 \cdot 1 \\
154 \cdot 1\end{array}$ & $\begin{array}{l}162.0 \\
160.3 \\
151.9 \\
159.0 \\
187.8\end{array}$ & $\begin{array}{l}121 \cdot 2 \\
116.4 \\
112.9 \\
120.5 \\
137.6\end{array}$ & $\begin{array}{l}1 \cdot 34 \\
1 \cdot 38 \\
1 \cdot 35 \\
1 \cdot 32 \\
1 \cdot 36\end{array}$ \\
\hline $\begin{array}{l}1953 \\
1954\end{array}$ & $\begin{array}{l}142 \cdot 0 \\
119.0\end{array}$ & $\begin{array}{l}162 \cdot 3 \\
137 \cdot 0\end{array}$ & $\begin{array}{l}132 \cdot 1 \\
110 \cdot 2\end{array}$ & $\begin{array}{l}1 \cdot 23 \\
1 \cdot 24\end{array}$ \\
\hline
\end{tabular}

Note: A change was made between 1952 and 1953 in the official definition of "usual residence" of deceased persons (see text).

Possible Effects of Bias in the Material and METHODS.-In his study of local variations in cancer mortality, Stocks (1947) stated that:
The advantage of studying variations within London is that standards of certification, diagnosis, and treatment ... may be regarded as almost constant over that area.

Despite this authoritative opinion, it is worth giving further consideration to the view that variations in diagnostic practice may be responsible for some part of the apparent contrasts within London, as well as between London and the rest of the country. It is, of course, impossible to make any direct estimate of the frequency of unrecognized errors. What can be done is to make reasonable, or deliberately extreme assumptions about these errors and calculate how serious their effects would be. The present problem may be approached in the following way. Suppose that in the country as a whole fraction $x$ of the deaths which ought to be certified as due to respiratory disease are in fact allocated to other causes, but that in London this fraction is only $\lambda$ times as great $(0<\lambda<1){ }^{*}$ Then, if the true risk of death from respiratory disease is the same in London as elsewhere, the London S.M.R. will be $100 \frac{(1-\lambda x)}{(1-x)}$. For example, if the total number of respiratory deaths in the country is as much as one-third greater than the number actually certified, and if London doctors make only half as many mistakes in certification as the average doctor, then the London S.M.R. would be 117 , compared with the actual figure of 137 . Any smaller margin between the true and the certified numbers of respiratory deaths, or between the proficiency of London and provincial doctors would give rise to an S.M.R. less than 117. Opinions will differ on what are plausible values for $x$ and $\lambda$, but it seems unlikely that any choice of values would explain more than half of the apparent London excess. The same argument may be used to arrive at the likely magnitude of any spurious variation within London. For example, if one-quarter of the respiratory deaths in Hampstead were otherwise certified, then the highest possible S.M.R. that could be recorded for any area with the same true risk as Hampstead would be 127; yet nineteen of the London boroughs had S.M.R.s higher than this.

It has sometimes been suggested that a high death rate from "senility" in any area indicates a low standard of diagnosis, and vice versa. If this be so, statistics of death from this cause (I.C.D. No. 794) provide an alternative basis for dealing with the present problem. As already mentioned, the London S.M.R. for this condition was very low (39), thus confirming a relatively high standard of certification

* These are meant to be net values: some of the mistaken allocations will be balanced by deaths wrongly attributed to respiratory disease. 
in the capital. It was also clear that death attributed to senility was rare even by London standards in some boroughs (Hampstead, Islington, St. Pancras) while in others it was common (Kensington, Paddington, Wandsworth, Woolwich). In particular, the S.M.R. for senility was lower in the twelve boroughs of Section A (32) than in the rest of the County (45), implying that certification was more precise in the area with the higher apparent mortality from respiratory disease. The importance of this finding can easily be assessed if we are prepared to assume that there is a simple statistical relationship between the frequency with which doctors resort to the term senility and their propensity to certify respiratory disease as the cause of death. The method may be visualized by means of a graph (Fig. 3), one axis measuring the proportion of respiratory deaths attributed to nonrespiratory causes and the other measuring the S.M.R. for senility. (It is best for this purpose to base the expected numbers of deaths from senility on the local numbers of deaths in each age group rather than on the living populations-this will help to discount the effect of any true variation in the local risk of death from senility). Two points are needed to fix the graph: these are plotted at $P$ (the senility S.M.R. of 100 and the assumed value of $x$ for England and Wales), and at $\mathbf{Q}$ (representing the ideal case in which all respiratory deaths are correctly diagnosed and the senility S.M.R. is at some minimum

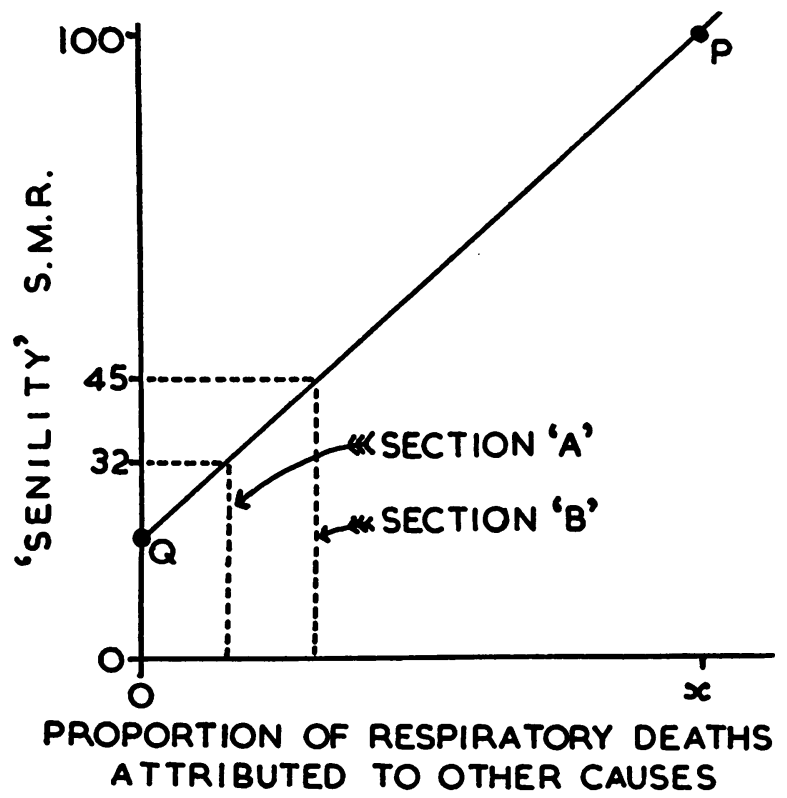

Fio. 3.-Imaginary relationship between two measures of local diagnostic efficiency value between 0 and the lowest value actually observed). It is then possible to read off the estimated proportion of respiratory deaths overlooked in, for example Sections A and B, and hence the likely magnitude of the spurious variation in the respiratory S.M.R.s. As before, the outcome of the argument will depend on what is considered a likely value of $x$ and also of the minimum death rate from senility. Experiment shows that this argument could conceivably explain a London S.M.R. of anything up to 130 , but that on no assumptions whatsoever could it explain more than one seventh of the observed contrast between Sections A and B.

One other possible source of spurious variation in the Borough S.M.R.s deserves mention. Since the respiratory S.M.R.s for London as a whole increased rapidly with age (Fig. 2), it follows that boroughs with populations of contrasted age-composition would have differing S.M.R.s even if their age-specific death rates were identical. The boroughs are, however, so similar in age-composition that, given the observed relationship between respiratory S.M.R. and age, no two borough S.M.R.s would differ on this account by more than four or five points. Moreover the older populations are found in the West London boroughs which recorded relatively low respiratory death rates, so that the small amount of bias introduced in this way would tend to cause an underestimate of the true differences.

It is realized that arguments of this kind cannot be developed with any great rigour. They have been discussed at some length because, when imperfect mortality statistics are under discussion, the acceptance or rejection of a finding is frequently decided by personal preference. A serious attempt to gauge the systematic as well as the sampling errors may often show where the balance of probability lies. In the present case it can be seen that nearly all the apparent variation within London in the risk of death from respiratory disease must be accepted as genuine. The high respiratory S.M.R. for London as a whole is less certain, but there is some circumstantial evidence (in the age-specific death rates for all causes) for accepting this finding also. It follows that the great bulk of "preventable" deaths in London, under present circumstances, are caused by respiratory disease. The number of such deaths is probably not less than 2,000 per annum in "normal" years.

\section{Part II. Relation of Borough Death Rates to CERTAIN SOCIAL INDICES}

REgRESSION ANALYSIS.-To what extent can these local mortality variations be explained by socio- 
economic factors? This question has some methodological interest as well as the intrinsic interest of the subject. It is usual to pursue such an inquiry by calculating the simple or multiple regression of local mortality rates on the various social indices which can be derived from census returns. Authors of such studies are always careful to avoid expressly identifying correlation with causation. Nevertheless there is an implicit assumption-without which these studies would lose most of their point-that the magnitude of the correlation coefficients obtained, or the proportion of variance "explained", does bear some relation to the aetiological importance of the factors (such as overcrowding or poverty) which these indices are taken to represent. A bold statement of this assumption was given by Stein in her study of tuberculosis rates in Glasgow (Stein, 1952):

'Explained' variance measures the extent to which the estimate represented by the regression equation agrees with the mortality (or incidence) rates actually observed, thus it indicates the magnitude of the contribution of that social factor to mortality (or incidence) ...

The combination of these four social factors 'explains' so large a proportion of the variance arising from ward differences in tuberculosis that little remains to be explained by some unknown factor. . . The investigation of small homogeneous areas reveals that the inequalities in incidence in this disease are very largely accounted for by disparities in social conditions. Moreover ... it is possible to estimate the separate contribution of each social component to the divergencies in respiratory tuberculosis. (Italics inserted).

It will now be shown that, if this assumption were sound, most of the variance of the borough respiratory death rates would be "accounted for" in terms of differences in social status with or without separate consideration of crowding indices. This would imply that little remained to be explained by any such factor as atmospheric pollution. But it will also be argued that no simple model relating risk of death to social status or crowding can, in fact, explain more than a fraction of the observed variation.

The correlations of the borough S.M.R.s for respiratory and other diseases with certain social indices are shown in Table VI. Density of population per acre bore no significant relation to either set of death rates. Density of population per room was more closely related to the death rates, but the magnitude of the coefficients obtained depended very largely on the particular index used. Thus percentage of population housed at densities greater than two and greater than one-and-a-half per room gave correlations with the respiratory S.M.R.s of +0.343 and +0.519 respectively, while average number of persons per room gave a coefficient of $+0 \cdot 791$. (From a similar finding in the Glasgow tuberculosis study
TABLE VI

CORRELATION BETWEEN BOROUGH S.M.R.S AND CERTAIN SOCIAL INDICES

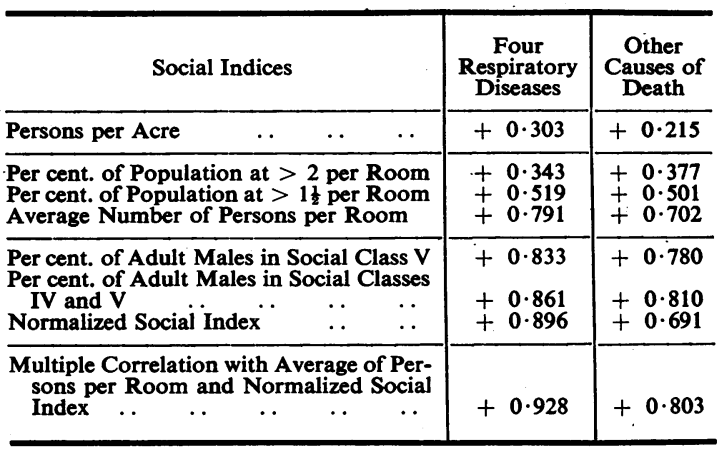

Stein (1952) inferred that so-called "ordinary crowding" was a more important influence on ward mortality rates than "overcrowding".) The next factor to be considered was economic status as judged from Table 27 of the County Census Report (RegistrarGeneral, 1953) which shows the social class distribution of the adult males in each borough. The correlations with this factor were higher than those with density of household and less dependent on the form of index used. The highest coefficient obtained was with a normalized social index* which served by itself to "explain" 80 per cent. of the variance of the respiratory S.M.R.s. When average number of persons per room and the normalized social index were taken together in a multiple regression equation, the total proportion of variance "explained" was increased by a further 6 per cent. Since either of these variables by itself "explains" more than half the variance of the respiratory group S.M.R.s, it might seem justifiable to conclude that the factors they measure were indeed responsible for the bulk of the variation observed. The possibilities of explanation by each of these factors will now be considered in turn.

Social Class.-The hypothesis to be considered is that members of a specified social class have the same S.M.R. in whatever part of London they live, and that borough S.M.R.s differ because borough populations contain members of each class in different proportions. Since these proportions are known, it is possible to predict what the borough S.M.R.s ought to be for any set of social class S.M.R.s we care to assume. Two such predictions have been made:

\footnotetext{
- Computed according to the method described by Martin (1949) but using the national social class distribution, from the One Per Cent. Sample Tables (Registrar-General, 1952), as the standard.
} 
(i) Assuming respiratory S.M.R.s for Social Classes $I-V$ in the ratio $1: 2: 3: 4: 5$;

(ii) Assuming non-respiratory S.M.R.s in the ratio 9 for Social Classes I and II, 10 for Class III, and 11 for Classes IV and V.

In each case the absolute values were fixed so as to give a predicted S.M.R. of 100 for England and Wales as a whole. These assumed ratios between the class S.M.R.s were based on a consideration of the most recent Occupational Mortality Tables (Registrar-General, 1954b), but were deliberately set on the extreme side. The borough S.M.R.s predicted in this way preserved a high correlation with the S.M.R.s actually observed $(+0.901$ for the respiratory diseases and +0.701 for all causes of death). But the crucial test of the hypothesis is not the size of the correlation between predicted and observed S.M.R.s; it is the size of the discrepancies between prediction and observation. By this criterion the hypothesis was quite inadequate, since it led to predicted S.M.R.s whose variances were only one-ninth of the variances observed, both for the respiratory and for the other causes of death. Thus, even with unit correlations, and a constant correction term, the Social class hypothesis could not account for more than 11 per cent. of the observed variance.

A more favourable result might have been obtained if the five social classes could have been divided into more homogeneous sub-groups, and a separate allowance made for the proportion of the borough population belonging to each sub-group. But even if this refinement doubled the variance of the predicted S.M.R.s for respiratory disease, this would amount to a mere quarter of the variance apparently "explained" by the regression of S.M.R.s on the normalized social index. A further serious fault in the hypothesis was that the predicted S.M.R. for London as a whole was only 101, compared with the observed value of 137 . In fact the hypothesis could not, on any assumptions, explain an S.M.R. for London as a whole greater than 115 (the value predicted for the extreme case in which all social classes except the lowest are assumed to have S.M.R.s of 0). In short, social class composition fails to explain more than a small fraction of the borough differences in respiratory mortality.

Density of Household.-Since the number of persons at risk at any level of household density can be calculated for each borough (see Table 11 of the Census County Report: Registrar-General, 1953) it is possible to work out the consequences of this hypothesis also. In this case, however, there are no tables like the Occupational Mortality Tables to suggest reasonable values of the S,M,R,s for people living at different densities. A set of predicted S.M.R.s was therefore calculated on the trial assumption that relative risk of death from respiratory disease for persons in households at densities of $<1,1$, and $>1$ per room were in the ratio 1:3:5. As before, the assumed relative risks were scaled to predict an S.M.R. of 100 for the whole country. The borough S.M.R.s so predicted showed fully as high a correlation with the observed S.M.R.s $(+0.766)$ as had been obtained in the original analysis using average number of persons per room. But the standard deviation of the predicted S.M.R.s was much less than half that of the actual S.M.R.s, so that, even with unit correlation, only 18 per cent. of the observed variance could be accounted for in this way, and, with the actual correlation, only 11 per cent. Experiment shows that probably the best prediction obtainable from the density hypothesis was achieved by assuming that risk of death from respiratory disease is zero for persons housed at less than one per room and equal for persons at all greater densities. Even on this absurd basis, and with a constant term to correct for a difference of fourteen points between the predicted and observed S.M.R.s for all London, the variance accounted for only 19 per cent. Thus the density hypothesis must also be regarded as a failure.

It is fair to conclude that, on reasonable assumptions about the relations between respiratory mortality and these two social factors, each can account for about 11 per cent. of the observed variance in the borough S.M.R.s. The correlation between these factors is of the order of $+0 \cdot 7$. It might therefore be thought that, in combination, they would account for more than 22 per cent. of the variance. Reflection shows that this is not the case, since any hypothesis about the combined effect of these factors would require new and less extreme assumptions about the net effect of each. In short, the 86 per cent. of the variance apparently "explained" in the regression analysis shrinks on examination to something between 20 and 25 per cent. This illustrates the danger of basing any aetiological argument directly upon a regression analysis of the conventional kind. In the present case it is clearly necessary to postulate at least one other factor which can increase the risk of death-particularly death from respiratory disease-and which is strong in east-central London. The most obvious factor for consideration is atmospheric pollution.

\section{Part III. Relation of local Death Rates to ATMOSPHERIC POLLUTION}

It has been conclusively shown that exceptional atmospheric conditions in London can have an 
important effect on the contemporary death-rate. The incident which has received most attention was that of December, 1952, in which, it is estimated, some 4,000 people lost their lives. Most studies of London fog (e.g. Russell, 1924 and 1926; Logan, 1953, 1956; Martin, 1953; Smithard, 1954; Waller and Lawther, 1954) have been exclusively concerned with short-term fluctuation of the death-rate. Consequently it is still possible to doubt whether atmospheric pollution causes any important net excess of deaths in the long run. The following comment by the official committee appointed to inquire into the disaster of 1952 is typical of a common view:

The fog was, in fact, a precipitating agent operating on a susceptible group whose life expectation, judging from their pre-existing diseases must, even in the absence of fog, have been short. (Ministry of Health, 1954).

Nevertheless, studies based on mortality in the County Boroughs suggest that there may be a measurable relationship between the "normal" level of air pollution and the risk of lung cancer (Stocks, 1949; Stocks and Campbell, 1955) as well as of bronchitis and pneumonia (Pemberton and Goldberg, 1954; Daly, 1954). Two of the chief difficulties facing such studies are:

(i) To obtain a satisfactory measure of the air pollution to which a defined population has been exposed. This difficulty is probably at a minimum in the County of London where there are now more than a hundred recording stations in an area of only 117 square miles.

(ii) To distinguish the effect of atmospheric pollution from the effects of the adverse climatic and social factors with which pollution tends to be associated.

Since climatic differences between the London boroughs must be negligible by comparison with the differences between the County Boroughs, this again makes London a good area for study. It has also been argued in the preceding section that, when due allowance has been made for the influence of social factors, the greater part of the variance of borough S.M.R.s from respiratory disease-probably more than three-quarters-still remains to be explained in some other way. Thus neither climatic nor social factors should have too serious an effect on any relationship which may be found between atmospheric pollution and mortality rates in different parts of London.

The measure of atmospheric pollution which is available for the greatest number of places is the concentration of sulphur dioxide, as judged from from the formation of sulphate on the surface of a standard lead peroxide candle (Department of Scientific and Industrial Research, 1955, 1956). Although routine measurements are now made by this method at a large number of sites in the London area, these sites are by no means evenly distributed over all the boroughs, and some instruments have been deliberately located at exceptional rather than at representative points. It is not yet possible to obtain valid average measurements for areas as small as the individual boroughs; this may explain why the study of Scott (1955) showed no significant relation between atmospheric pollution and lung cancer. Convenient alternative units of study are the Public Health Divisions, of which London has nine. Use of these larger units may also help to control an error which does not arise with social class or household density, namely that caused by persons who reside in one borough but spend their working lives in another where the atmosphere may be quite different.

It is important to average the pollution measurements over a sufficient period of time because of the large fluctuations associated with hour of the day, day of the week, and season of the year. However, there does not appear to be much advantage in averaging over periods longer than a full year, since trend changes in air pollution are quite small compared with local differences. It was therefore decided to use the average of the $\mathrm{SO}_{2}$ determinations at all recording sites in each Public Health Division during the most recent period of twelve months for which information was available (Jan.-Dec., 1955).

It was shown in the first section of this paper that the respiratory S.M.R.s for London as a whole increased rapidly with age. This suggests the need for an index of atmospheric pollution which measures the duration as well as the intensity of the exposure. The County Report of the Census provides a rough means of obtaining such an index since it shows (Table 19) the number of residents of each borough who were born in London. Hence one can calculate the percentage of each borough or district population which has been exposed to the London environment since birth-a percentage which varies from 35 in Westminster to 83 in Bermondsey and Bethnal Green. This percentage multiplied by the mean $\mathrm{SO}_{2}$ determination probably yields a fairly good comparative index of the exposure of each Divisional population to atmospheric pollution.

Since only nine pairs of observations were available, rather high correlation coefficients were necessary to establish any significant relation between this index of air pollution and mortality rates. Nevertheless, as Table VII shows, the coefficients obtained were all of border-line or definite significance. In particular the coefficient for the aggregate of the four respiratory diseases was significant at $+0 \cdot 858$, thus "explaining" 74 per cent. of the district variance. Somewhat unexpectedly the correlation coefficient 
for non-respiratory diseases was higher still - a result apparently depending on the district pattern of mortality from heart disease. A better basis of comparison between diseases than the correlation coefficients is provided by the regression coefficients, which are shown in the second column of Table VII and illustrated for the two main disease groups in Fig. 4. If these regression coefficients can be taken at their face value, they indicate that air pollution exerts an effect on mortality from bronchitis about seven times as great as on mortality from most non-respiratory diseases, with intermediate effects on pneumonia, respiratory tuberculosis, lung cancer, and heart disease, in that order. They also imply that with completely "clean" air respiratory mortality in London could be cut by about one-half, and mortality from other causes by about one-fifth.

\section{TABLE VII}

RELATION BETWEEN MORTALITY IN THE NINE PUBLIC HEALTH DIVISIONS OF LONDON AND AN INDEX OF EXPOSURE TO ATMOSPHERIC POLLUTION

\begin{tabular}{|c|c|c|c|}
\hline & & $\begin{array}{l}\text { Correlation } \\
\text { Coefficient }\end{array}$ & $\begin{array}{l}\text { Regression } \\
\text { Coefficient }\end{array}$ \\
\hline $\begin{array}{l}\text { Four } \\
\text { Respiratory } \\
\text { Diseases }\end{array}$ & $\begin{array}{lll}\text { Aggregate } & . & \ldots \\
\text { Bronchitis } & \ldots & \ldots \\
\text { Pneumonia } \\
\text { Respiratory } \\
\text { Cancer of the Luberculosis } \\
\text { Cang } & \ldots\end{array}$ & $\begin{array}{l}+0.858 \\
+0.785 \\
+0.651 \\
+0.822 \\
+0.696\end{array}$ & $\begin{array}{l}+0.412 \\
+0.533 \\
+0.364 \\
+0.306 \\
+0.290\end{array}$ \\
\hline $\begin{array}{l}\text { Other } \\
\text { Causes of } \\
\text { Death }\end{array}$ & $\begin{array}{l}\text { Aggregate } \\
\text { Heart Disease } \\
\text { All other Causes }\end{array}$ & $\begin{array}{l}+0.896 \\
+0.918 \\
+0.655\end{array}$ & $\begin{array}{l}+0.102 \\
+0.150 \\
+0.071\end{array}$ \\
\hline
\end{tabular}

Critical values of correlation coefficient for nine pairs of observations: 5 per cent., $0 \cdot 666 ; 2$ per cent., $0 \cdot 750 ; 1$ per cent., $0 \cdot 798$

There are, however, a number of dangers in any too literal interpretation of the results. In the first place, some part of this empirical association must be due to factors whose geographical distribution within London happens to be similar to that of the air pollution index. Probably the most important of these are the social factors discussed in the preceding section. Secondly, the index devised to represent exposure to polluted air is a statistical hybrid: its appropriateness depends on a particular interpretation of the finding presented in Fig. 2. Finally, even if the true association between mortality and air pollution is as strong as Table VII suggests, it does not follow that sulphur dioxide is necessarily responsible for all or even most of the damage.

\section{SUMMARY}

An analysis has been made of the mortality statistics of the metropolitan boroughs for the years 1950-52. The total number of deaths during this period was not excessive by national standards, but a break-down by sex and age suggests that there

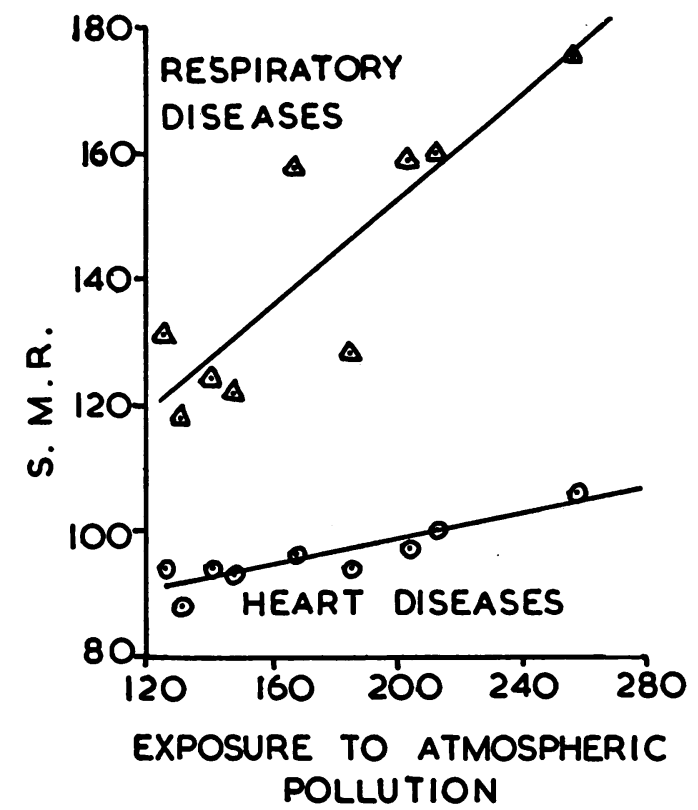

Fig. 4.-Relationship between mortality in the nine Public Health Divisions of London and an index of exposure to atmospheric pollution (see text).

were in fact some thousands of "extra" deaths among males generally and in particular among the 45-64 age group. The All Causes S.M.R.s, by age, sex, and borough were very similar to those of twenty years earlier.

The outstanding feature of the analysis by cause of death was an excess (mounting rapidly with age) in the deaths from a group of respiratory diseases comprising bronchitis, pneumonia, cancer of the lung, and respiratory tuberculosis. Borough deathrates indicate an area of exceptionally high respiratory mortality (more than 50 per cent. above the national level) in the east-central region of London. This section suffered a similar excess relative to the rest of the county in an influenza year, in the year of the smog disaster, and in the preceding three "normal" years.

The possible effect on these findings of errors in death certification are discussed.

The borough mortality rates correlate closely with indices of social status and crowding and, in a superficial sense, something between 80 and 90 per cent. of the variance of the borough S.M.R.s for respiratory disease can be "explained" by these social factors. When the relationships are examined more closely, however, it is found that they really explain very little, and that the bulk of the observed variation must be due to some other factor or factors-very 
possibly including atmospheric pollution. The statistics are, in fact, consistent with the hypothesis that air pollution, besides its well-known short-term effect, exerts an important influence on the long-term deathrates from respiratory disease (especially bronchitis), and a smaller influence on the mortality from heart disease.

I am greatly indebted to Dr. Alice Stewart for advice and for criticism of the drafts.

\section{REFERENCES}

Daly, C. (1954). Brit med. J., 2, 687.

Department of Scientific and Industrial Research (1955). "The Investigation of Atmospheric Pollution: A Report on Observations in the 10 Years ended 31st March, 1954. Twenty-seventh Report". H.M.S.O., London.

(1955), Atmosph. Pollut. Bull., vol. 22, Nos. 10 to 12 ; vol. 23 , Nos. 1 to 9 . H.M.S.O., London.

Eastcott, D. F. (1956). Lancet, 1, 37.

Farr, W. (1885). "Vital Statistics". Offices of the Sanitary Institute, London.

General Register Office (1952). "Census, 1951. Great Britain. One Per Cent Sample Tables. Part I". H.M.S.O., London.

- (1953). "Census, 1951. England and Wales. County Report: London". H.M.S.O., London. Report: Essex". H.M.S.O., London.
Logan, W. P. D. (1953). Lancet, 1, 336.

(1956). Brit. med. J., 1, 722

Martin, W. J. (1949). "The Physique of Young Adult Males". Medical Research Council Memorandum, No. 20. H.M.S.O., London. (1953). Med. Offr., 90, 223.

Ministry of Health (1954). "Mortality and Morbidity during the London Fog of December 1952". Reports on Public Health and Medical Subjects, No. 95. H.M.S.O., London.

Pemberton, J., and Goldberg, C. (1954). Brit. med. J., 2, 567.

Registrar-General for England and Wales. Annual Statistical Review, Tables, Part I. Medical for 1930-32 (published 1931-33) and for 1942-54 (published 1946-55), including Corrigenda for 1953 (published 1954). H.M.S.O., London.

C (1932). "Census of England and Wales, 1931. County of London". H.M.S.O., London.

Wales. 1951. Occupational Mortality. Part I". H.M.S.O., London Russell, W. T. (1924). Lancet, 2, 335.

(1926). Ibid., 2, 1128.

cott J. A. (1953). "Report of the County Medical Officer of Health and School Medical Officer for the year, 1952". Staples, London. - (1955). "Report of the County Medical Officer of Health and School Medical Officer for the year 1954". Appendix A: Lung Cancer, 1931-54, p. 144. Staples, London.

Smithard, E. H. R. (1954). Monthly Bull. Min. Hlth., 13, 26.

Stein, L. (1952). Brit. J. soc. Med., 6, 1.

Stocks, P. (1947). "Regional and Local Differences in Cancer Death Rates". General Register Office. Studies on Medical and Population Subjects, No. 1. H.M.S.O., London. and Campbell, J. M. (1955). Brit. med. J., 2, 923.

Waller, R. E. and Lawther, P. J. (1955), Ibid, $2,1356$.

World Health Organization (1949). "Manual of the International Statistical Classification of Diseases, Injuries, and Causes of Death", Sixth Revision. H.M.S.O., London. 
APPENDIX TABLE

MORTALITY FROM PARTICULAR CAUSES: LONDON A.C., 1950-52

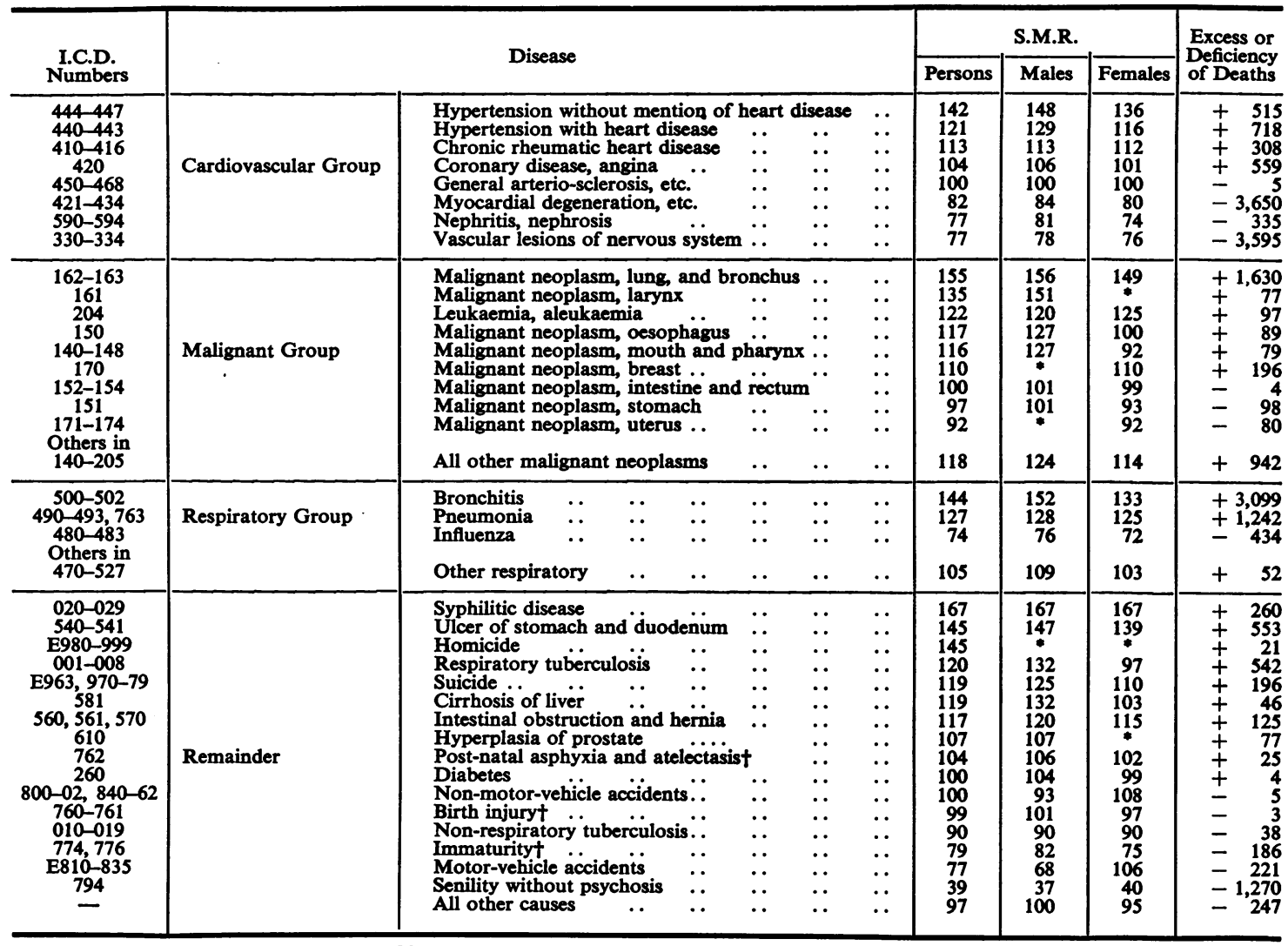

- Less than fifty deaths recorded + Expectation based on numbers of live births 